\title{
Firing Shrinkage of Porcelain-resin Composites Prepared by Laser Lithography
}

\author{
Noriyuki SATOH, Yasuo UEDA, Takumi YORIMOTO, \\ Hideki AITA, Shingo MATSUO, Noboru OHATA \\ and Fumio WATARI ${ }^{1}$ \\ Department of Crown and Bridge Prosthodontics and \\ ${ }^{1}$ Department of Dental Materials and Engineering, \\ Hokkaido University School of Dentistry, \\ Kita 13 Nishi 7 Kita-ku, Sapporo, 060-8586, Japan
}

Received May 21, 1999/Accepted September 13, 1999

\begin{abstract}
Using porcelain and resin-mixed composites as experimental materials, cubic polymerized composites were prepared by the accumulation of thin slices cured by laser scanning. The composites were then fired, and bulk ceramic bodies were made. The optimal firing conditions of polymerized composites and firing shrinkage were investigated. The results showed that cubic ceramic bodies in a form homologous to that before firing could be reproduced. The volume shrinkage of fired ceramic bodies consisting of $1 \mathrm{~g}$ of ceramic powders and $0.3 \mathrm{~g}$ of epoxy resin was about $30 \%$ under all firing conditions, and there were no significant differences between specimens. It was suggested that with further research and development, three-dimensional forms for clinical use in dentistry could be manufactured by the proposed method.
\end{abstract}

Key words: Porcelain-resin composite, Laser scanning, Firing shrinkage

\section{INTRODUCTION}

Recently, esthetic dentistry has been in great demand, and prosthetic appliances manufactured by ceramics are being used extensively. A typical example is the porcelain-fused metal crown, which is esthetically pleasing and has high durability. However, advanced laboratory techniques and skilled handwork are required to make these prosthetic appliances. Manufacturing accurate three-dimensional (3-D) tooth forms by firing porcelain powders is especially difficult because of firing shrinkage and sintering. After firing porcelain powders, a great deal of skillful handwork is required to make an accurate 3 -D form. The aim of this study was to try to develop a method that can automate this difficult handwork.

Due to the advances in computer technology, CAD/CAM technology has recently been introduced to dentistry. Ueda ${ }^{1)}$ and Hikita et $a l^{2)}$ in our department have used $\mathrm{CAD} / \mathrm{CAM}$ technology to manufacture metal crowns and bridges, which have been successfully used in clinical practice. Making a 3-D form on the computer is relatively easy. A 3-D model of the maxillo-facial bone has been made in our department by laser lithography from CT data, and this model has proved to be useful in clinical diagnosis and treatment of maxillo-facial prosthodontics. This CAD/CAM technology is developing toward manufacturing of esthetic ceramic crowns. Commercialized 
automation methods for manufacturing ceramic crowns and many other methods ${ }^{3-6)}$, such as selective laser sintering of ceramics $^{7)}$, have been studied.

Meanwhile, Satoh formerly investigated the application of selective gold plating by laser scanning for the manufacture of a metal crown, but deposition of an adequate thickness of metal crown for selective plating was found to be very difficult ${ }^{8)}$. However, since CAD/CAM technology is an effective means for making a 3 -D form, we considered that the possibility of manufacturing a $3-\mathrm{D}$ form by ceramic powders instead of metal plating would be worthy of investigation. To facilitate making 3-D form by ceramic powders, a small amount of resin was mixed as a binder. The method proposed here is another approach to the automation of manufacturing of ceramic crowns.

In this study, we have developed a new technique for manufacturing dental ceramics that combines computer technology and the manual building-up of ceramic powders. Using porcelain and resin-mixed composites as experimental materials, accurate 3-D form polymerized composites were made by the accumulation of thin slices cured by laser scanning. To obtain uniform shrunk bulk ceramic bodies, the binding resin was then fired and the porcelain was carefully sintered. This new method is associated with many problems including shrinkage, deformation, residual resin, firing conditions and physical properties. The main problem is whether uniform shrinkage and reduced deformation can in fact be achieved by this method. Therefore, we initially focused on the firing shrinkage of porcelain-resin composites, and a simple cubic form was selected for the experiments. The optimal firing conditions of polymerized composites and firing shrinkage were investigated. The clinical applicability of our new technique is discussed in this paper.

\section{MATERIALS AND METHODS}

Porcelain powder (Noritake super porcelain AAA translucent T0, Noritake, Tokyo, Japan) and a UV-cured epoxy resin (Adika rascure HS662, Asahi Electric Corp, Tokyo, Japan) were used in this study. The porcelain powders and epoxy resin were mixed uniformly at a weight ratio of $10: 3$, since a smaller powder-liquid ratio would induce large shrinkage and deformation. This porcelain-resin composite was used as the experimental material.

A laser lithography machine (SOUP, NTT data CMET, Tokyo, Japan) was used to make 3-D forms of the porcelain-resin composites. In laser lithography, 2-D slices of epoxy resin patterns cured by a scanning laser are accumulated to make a 3-D form along the $z$ axis. In this study, porcelain resin composites were used instead of epoxy resin. First, $0.2 \mathrm{~mm}$-thick porcelain resin composites were built up to make a smooth surface for the standard plane by hand using a spatula because of the high consistency. Second, a square pattern of $1 \times 1 \mathrm{~cm}^{2}$ was scanned by an He-Cd laser (wave length: $325 \mathrm{~nm}$ ), and a thin slice was cured. Then, $0.2 \mathrm{~mm}$-thick porcelain resin composites were built up manually again and cured repeatedly. Each slice was cured on the previously cured slice, and a total of 50 slices were accumulated to make a 
cubic-shaped polymerized composite of $1 \times 1 \times 1 \mathrm{~cm}^{3}$. Fig. 1 shows the fabrication method of the porcelain-resin composite by laser lithography. Fig. 2 shows an example of a polymerized composite.

The composites were fired under three conditions, as shown in Table 1. The first firing stage was intended for burning-out of the resin, and the second firing stage was intended for sintering porcelain powders. In the second firing stage, since the shape of composites changed greatly when they were fired in air or in a vacuum, we made a $3 \times 3 \times 3 \mathrm{~cm}^{3}$ glass-fiber box (Torch Wool, Nisshin, Tokyo, Japan). A polymerized composite was placed in the box with high melting point quartz powders (Moon Flint, Morita, Tokyo, Japan) filled around it and then fired. The quartz powders were intended as support materials when sintering occurred, and uniform shrinkage was expected. Firing condition 1 had the largest heat rate to high holding temperature in the first firing stage and was characterized by a quick firing time. Firing condition 2 was characterized by a lower holding temperature and longer firing. Firing condition 3 was distinguished from the other conditions by a very low heat rate in the first firing stage. The very low heat rate was established to prevent

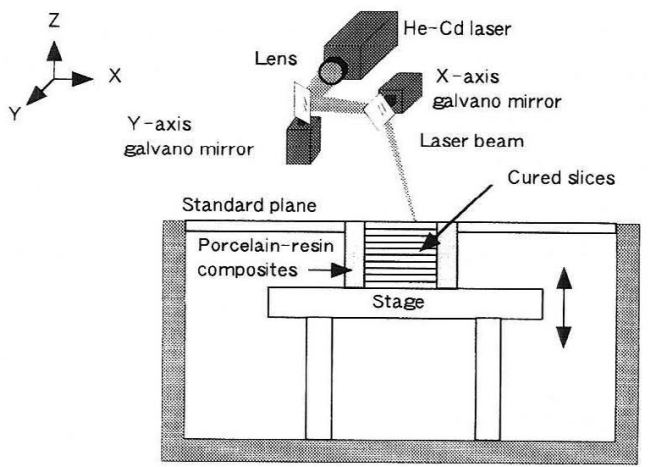

Fig. 1 Fabrication method of porcelainresin composite by laser lithography.

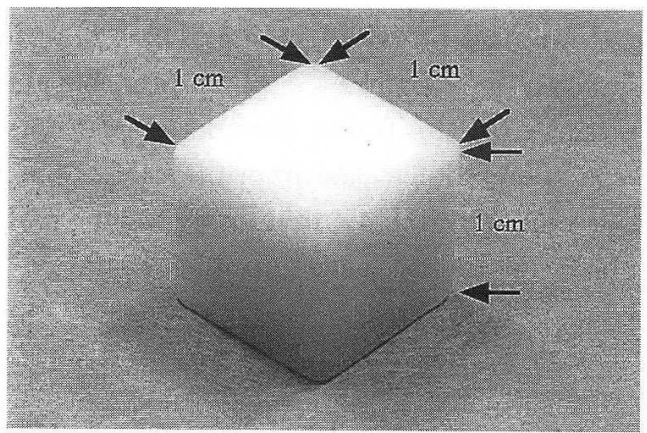

Fig. 2 An example of a polymerized composite.

Table 1 Firing conditions of the specimens

\begin{tabular}{lcccccc}
\hline & \multicolumn{3}{c}{ First firing stage } & \multicolumn{3}{c}{ Second firing stage } \\
\hline & $\begin{array}{c}\text { Heat rate } \\
\left({ }^{\circ} \mathrm{C} / \mathrm{min}\right)\end{array}$ & $\begin{array}{c}\text { Holding } \\
\text { temperature } \\
\left({ }^{\circ} \mathrm{C}\right)\end{array}$ & $\begin{array}{c}\text { Holding } \\
\text { time } \\
(\text { hours })\end{array}$ & $\begin{array}{c}\text { Heat rate } \\
\left({ }^{\circ} \mathrm{C} / \mathrm{min}\right)\end{array}$ & $\begin{array}{c}\text { Firing } \\
\text { temperature } \\
\left({ }^{\circ} \mathrm{C}\right)\end{array}$ & $\begin{array}{c}\text { Firing } \\
\text { time } \\
(\mathrm{min})\end{array}$ \\
\hline $\begin{array}{l}\text { Firing } \\
\text { condition 1 }\end{array}$ & 30 & 560 & 24 & 60 & 850 & 10 \\
$\begin{array}{l}\text { Firing } \\
\text { condition 2 }\end{array}$ & 30 & 370 & 24 & 40 & 850 & 60 \\
$\begin{array}{l}\text { Firing } \\
\text { condition 3 }\end{array}$ & 0.5 & 370 & 24 & 40 & 850 & 60 \\
\hline
\end{tabular}




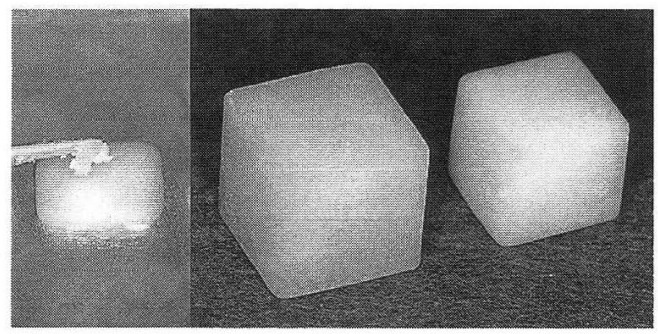

Fig.3 A composite during construction, and before and after firing.

Left: Constructing the porcelain-resin composite

Middle: A polymerized composite before firing

Right: A fired bulk ceramic body

Table 2 Linear shrinkage and volume shrinkage of specimens

\begin{tabular}{lll}
\hline & $\begin{array}{c}\text { Linear shrinkage (SD) } \\
\text { X- or Y-axis } \\
\text { Z-axis }\end{array}$ & Volume shrinkage (SD) \\
\hline Firing & $13.4(1.0)$ & $33.4(2.7)$ \\
condition 1 $(\mathrm{n}=3)$ & $11.3(1.5)$ & 32.7 \\
Firing & 12.2 & \\
condition 2 $(\mathrm{n}=1)$ & 12.7 & $31.1(1.8)$ \\
Firing & $10.9(0.8)$ \\
condition 3 $(\mathrm{n}=3)$ & $13.2(0.9)]^{*}$ & \\
\hline
\end{tabular}

Asterisk shows significant difference using Scheffe's post hoc test at $p<0.05$

deformation and cracks from causing quick burning-out of the resin. Three polymerized composites were made under conditions 1 and 3 , and one composite was made under condition 2. Fig. 3 shows a composite during construction, and before and after firing. The left photo shows the actual execution of construction of the porcelain-resin composites. The middle and right photos show the polymerized composite and fired bulk ceramic body, respectively.

Before and after firing, the length of each side of the cube was measured, and the linear shrinkage along the $\mathrm{Z}$-axis and $\mathrm{X}$-or $\mathrm{Y}$-axis and the volume shrinkage were calculated assuming that the fired ceramic bodies were cubes. Observations by SEM and the naked eye were also performed.

\section{RESULTS}

Table 2 shows the mean linear shrinkage and volume shrinkage of the specimens. Fig. 4 shows the ceramic bodies manufactured under firing conditions 1,2 and 3 . The 


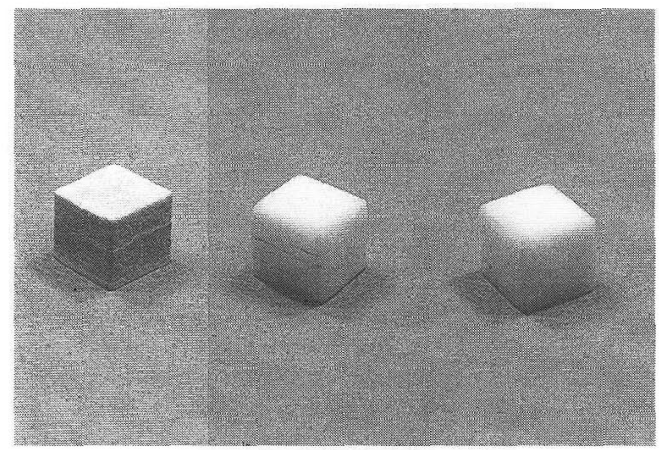

Fig. 4 Ceramic bodies manufactured by this method.

Left: A ceramic body manufactured under firing condition 1 .

Middle: A ceramic body manufactured under firing condition 2 .

Right: A ceramic body manufactured under firing condition 3 .

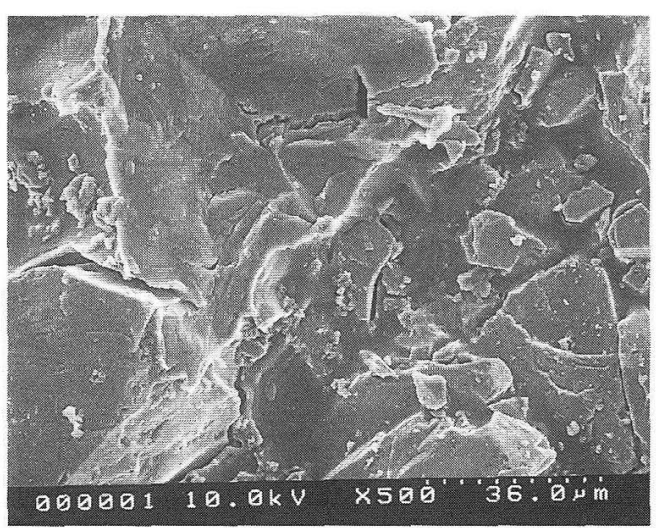

(a)

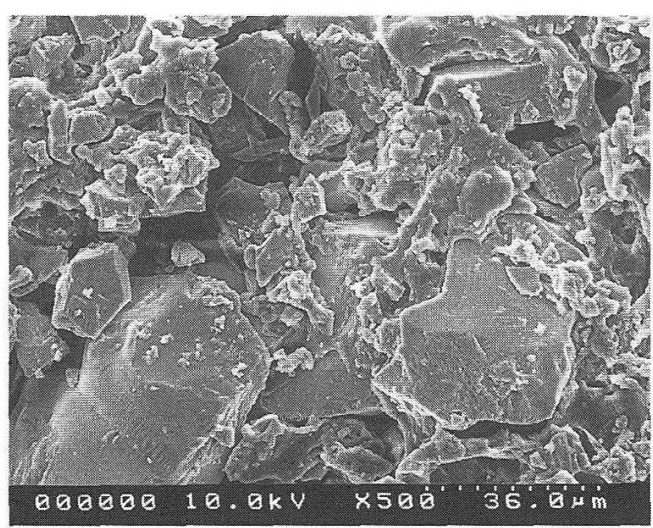

(b)

Fig. 5 SEM images of a porcelain-resin composite before firing.

(a) X-Y surface

(b) Accumulating surface

results of Scheffe's post hoc test showed that there was a significant difference in linear shrinkage between the $\mathrm{X}$-or $\mathrm{Y}$-axis and $\mathrm{Z}$-axis under firing condition 3 . The mean volume shrinkages were $33.4 \%, 32.7 \%$ and $31.1 \%$ under conditions 1,2 and 3 , respectively. There were no significant differences between these results. Fig. 5 shows SEM images of the surfaces of a polymerized composite ( $\mathrm{a}$ : $\mathrm{X}-\mathrm{Y}$ surface, b: accumulating surface). There are more gaps between porcelain powders in the accumulating surface image than in the $\mathrm{X}-\mathrm{Y}$ surface image. Observations with the naked eye showed 
that a bulk ceramic body fired under condition 1 had cracks within the interface of the slices, as shown in the left photo of Fig. 4. The color of the body was blackish, suggesting the presence of residual carbon. The cubic form was maintained to a certain extent. Fig. 6 shows SEM images of the ceramic surface after firing under condition 1. Many small particles can be seen in both images. A bulk ceramic body fired under condition 2 also had cracks within the interface (Fig. 4 middle). The color of the body was white. The line edge was roundish to some extent, but the cubic form was maintained overall. Fig. 7 shows SEM images of the ceramic surface after firing under condition 2. Small partictes and gaps are considerably less numerous

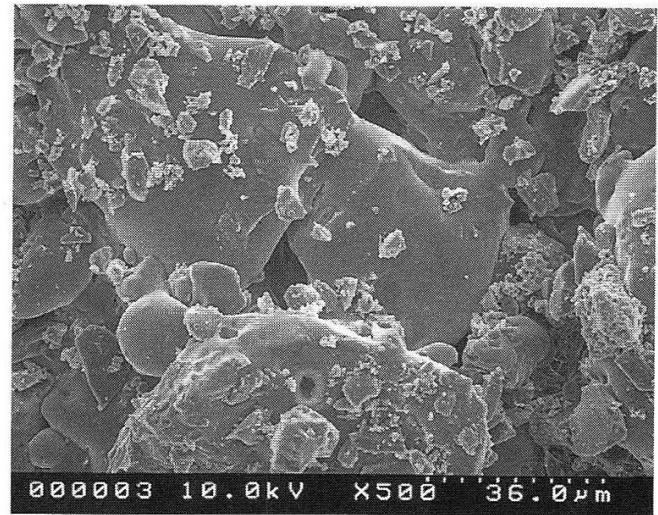

(a)

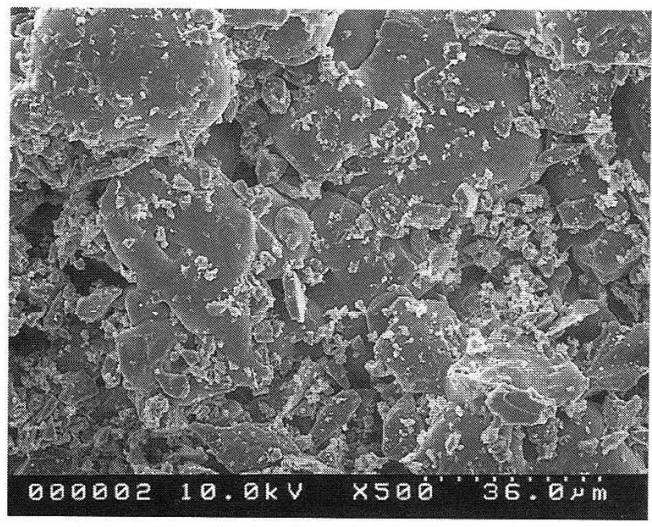

(b)

Fig. 6 SEM images of a ceramic body after firing under condition 1.

(a) $\mathrm{X}-\mathrm{Y}$ surface

(b) Accumulating surface

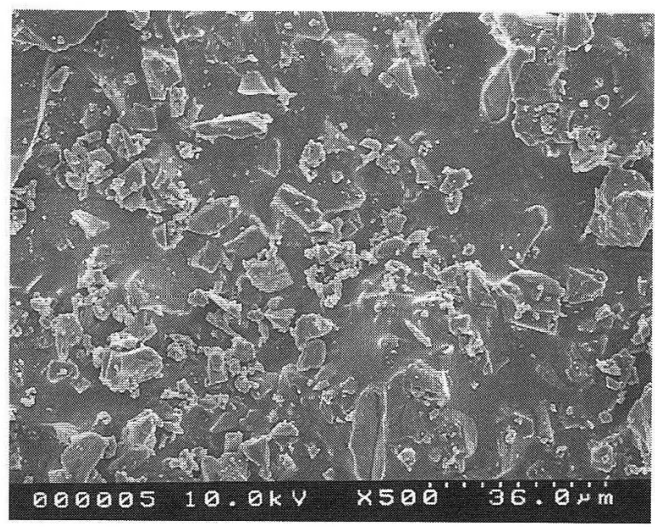

(a)

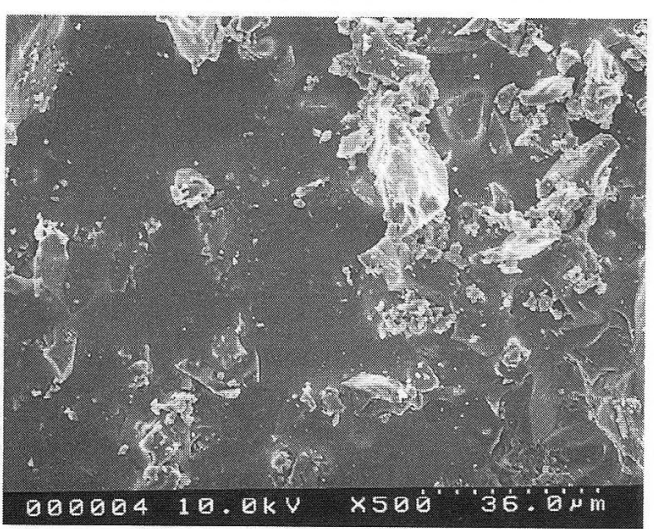

(b)

Fig. 7 SEM images of a ceramic body after firing under condition 2.

(a) X-Y surface

(b) Accumulating surface 


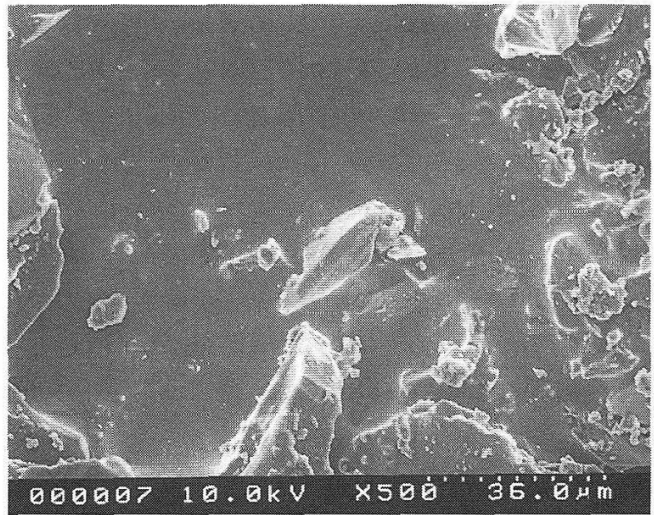

(a)

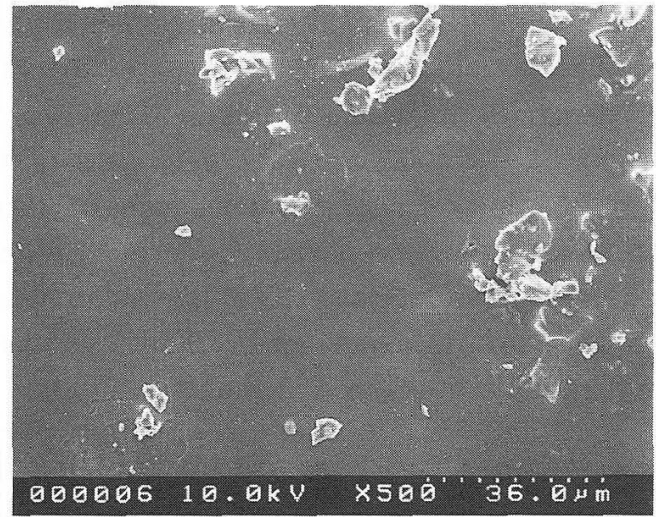

(b)

Fig. 8 SEM images of a ceramic body after firing under condition 3.

(a) $\mathrm{X}-\mathrm{Y}$ surface

(b) Accumulating surface

than in the images shown in Fig. 6. A bulk ceramic body fired under condition 3 had no cracks (Fig. 4 right). The cubic form was relatively well-maintained in spite of a roundish line edge. Fig. 8 shows SEM images of a bulk ceramic body surface after firing under condition 3. Porcelain powder remains in some places, but the surface is much smoother than those of specimens fired under conditions 1 or 2. Small particles and gaps can hardly be seen in either of the images.

\section{DISCUSSION}

The combination of porcelain powders and binding resin had an influence upon the results of this method. To prevent interception of the laser light, translucent powders were selected in this experiment. Dyed powders may influence the curing depth and resolution. The UV-cured epoxy resin was selected because of its high reproducibility of details. However, other combinations are possible such as using UDMA as binders from the point of easiness of firing.

The results of this study confirmed that cubic bulk ceramic bodies can actually be produced by this method of firing porcelain-resin composites. Thus, it is possible to automate the manufacturing of ceramic crowns by the use of laser lithography. In this study, square slices of $1 \times 1 \mathrm{~cm}^{2}$ in surface area and $0.2 \mathrm{~mm}$ in thickness were made by hand using a spatula. However, this process should ideally be automated. The automation process is greatly related to the mixture ratio. The mixture ratio of porcelain powder to resin is also related to the shrinkage. The measured volume shrinkage was $31-34 \%$, with no significant differences between specimens. The theoretical volume shrinkage of this mixture ratio was calculated from the porcelain density $\left(2.4 \mathrm{~g} / \mathrm{cm}^{3}\right)$ to be $39.2 \%$. Consequently, it is capable of shrinking slightly more. To reduce shrinkage, a higher proportion of porcelain powder must be used; however, 
a very high ratio of porcelain causes operational problems due to high consistency. It may also cause a decrease of curing depth or resolution due to scattering or absorption of laser light. In this experiment, the weight ratio of porcelain powders to epoxy resin was $10: 3$, which was thought to be the limit of consistency under manual operation.

Meanwhile, the linear shrinkage differed significantly between the X-or Y-axis and Z-axis under firing condition 3. Shrinkage along the $\mathrm{Z}$-axis was $2.3 \%$ greater than that along the $\mathrm{X}$-or $\mathrm{Y}$-axis, suggesting deformation had occurred. However, it cannot be concluded that firing under condition 3 induces deformation because the number of specimens was small. Further investigation using a larger number of specimens is needed. More complex forms such as crowns must be tested in the future, and a method to evaluate the reproducibility of a $3-\mathrm{D}$ form must be established ${ }^{9)}$.

Observations by SEM and the naked eye indicated that the optimal firing condition was condition 3. Ceramic bodies fired under condition 3 had no cracks between interfaces, and no small particles or gaps could be seen on SEM images. The blackish body color after firing under condition 1 suggested that the burning-out of resin was insufficient and that carbon remained in the ceramic body. The small particles seen in SEM images of specimens fired under condition 1 may be residual resin.

Our preliminary experiment showed that two-stage firing was desirable to maintain the form of the specimen. It was thought that burning-out of the resin occurred in the first firing stage and that sintering of porcelain powders occurred in the second firing stage. However, the results of experiments performed under conditions 1 and 2 suggested that burning-out of the resin and sintering of the porcelain occurred simultaneously in the second firing stage in spite of the long holding time in the first firing stage. A comparison of the results of experiments conducted under conditions 1,2 and 3 showed that holding for 10 minutes at $850^{\circ} \mathrm{C}$ is too short for the second firing stage to burn out the resin. The results of the experiment conducted under condition 3 indicated that a very low heat rate is desirable in the first firing stage to avoid cracking and deformation. More detailed investigation is needed to shorten the operation time.

\section{CONCLUSION}

Polymerized porcelain-resin composites were manufactured by the accumulation of UV-cured slices. The specimens were then fired under three conditions to obtain 3-D dental ceramics in a cubic shape. The results confirmed that bulk ceramic bodies could be manufactured by this method. The firing volume shrinkage and linear shrinkage were investigated, and the specimens were observed by SEM. The ceramic body manufactured under firing condition 3 showed a better firing state but deformation was thought to have occurred. Further investigation is needed to develop this method. 


\section{REFERENCES}

1) Ueda, Y.: A study of computer aided design system for tooth crown form, $J J p n$ Prosthodont Soc 40(5) : 163-173, 1996. (in Japanese)

2) Hikita, K., Yorimoto, T., Aita, H., Ueda, Y., Ohata, N., Uchiyama, Y., Ogino, M. and Sekiguchi, K.: The fabrication of titanium bridge used by CAD/CAM system, $J J p n$ Prosthodont Soc 42 (special issue 99) : 138, 1998. (in Japanese)

3) Kikuchi, M., Okuno, O.,Takakuda, K. and Miyairi, H.: An approach to computer aided porcelain forming system, $J J$ Dent Mater 13 (special issue 23) : 290, 1994. (in Japanese)

4) Kikuchi, M., Okuno, O.,Takakuda, K. and Miyairi, H.: An approach to computer aided porcelain forming system - porcelain firing-, $J J$ Dent Mater 13 (special issue 24) : 154, 1994. (in Japanese)

5) Kikuchi, M. and Okuno, O.: Computer aided porcelain forming system, $J J$ Dent Mater 14 (special issue 26) : 200, 1995. (in Japanese)

6) Kikuchi, M. and Okuno, O.: Computer aided porcelain forming system (Part 3) -Evaluation and control of porcelain wetness during forming-, $J J$ Dent Mater 16 (special issue 30): 144, 1997. (in Japanese)

7) Klocke, F. and Wirtz, H.: Selective laser sintering of ceramics, Rapid prototyping symposium 12 : 35-39, 1997.

8) Satoh, N.: A basic study on photoinduced metal deposition - The possibility of fabrication of metal crown-, Hokkaido J. Dent. Sci. 15(1): 20-45, 1994. (in Japanese)

9) Kikuchi, M. and Okuno, O.: Computer aided porcelain forming system (Part 4) - Shape measurement of porcelain during forming-, $J J$ Dent Mater 17 (special issue 31): 119, 1998. (in Japanese) 